\title{
A foot-care program to facilitate self-care by the elderly: a non-randomized intervention study
}

\author{
Shizuko Omote ${ }^{1 *}$, Arisu Watanabe ${ }^{2}$, Tomoko Hiramatsu ${ }^{3}$, Emiko Saito ${ }^{4}$, Masami Yokogawa', Rie Okamoto ${ }^{1}$, \\ Chiaki Sakakibara ${ }^{1}$, Akie Ichimori ${ }^{1}$, Kaoru Kyota ${ }^{1}$ and Keiko Tsukasaki ${ }^{1}$
}

\begin{abstract}
Objective: We aimed to evaluate a foot-care awareness program designed to improve foot morphology, physical functioning, and fall prevention among the community-dwelling elderly. Eleven independent community-dwelling elderly women (aged 61-83 years) were provided with foot-care advice and shown effective foot-care techniques to perform regularly for 6 months, and compared with a control group of 10 elderly women who did not receive any intervention. Measurements of foot form, functional capacity, subjective foot movement, and physical function were taken at baseline and 6-month follow-up.
\end{abstract}

Results: At follow-up, improvements were seen in the intervention group in foot morphology, subjective foot movement, foot pressure, and balance. In the intervention group, 90\% of women had maintained or improved foot form and none of them had fallen during the post-intervention period, compared to the control group where 30\% improved foot form ( $p=0.0075)$ and four $(40 \%)$ of them had fallen. Therefore, a foot-care program may have the potential to prevent falls and improve mobility among the elderly.

Trial Registration UMIN-CTR No. UMIN000029632. Date of Registration: October 19, 2017

Keywords: Program, Foot care, Self-care, Elderly, Support, Community

\section{Introduction}

The elderly are more likely to suffer from lower levels of self-care, increasing the chances of foot problems [1]. Keeping feet in good condition is essential for effective functioning, promoting leg strength, and reducing falls $[2,3]$. Much research has examined attributes of the foot in relation to adverse health consequences. For example, foot posture is linked to lower extremity joint pain [4], whilst toe muscle strength is associated with balance and falls among the elderly [5]. Studies on foot care by medical professionals for the dependent elderly have found improvements in blood circulation, muscle fatigue, and walking ability [6, 7]. In a randomized controlled trial,

\footnotetext{
*Correspondence: omotes@mhs.mp.kanazawa-u.ac.jp

${ }^{1}$ Faculty of Health Science, Institute of Medical, Pharmaceutical and Health Sciences, Kanazawa University, 5-11-80 Kodatsuno, Kanazawa, Ishikawa 920-0942, Japan

Full list of author information is available at the end of the article
}

Waxman and colleagues found elderly podiatry patients who received self-management foot-care instruction had lower foot disability scores at follow-up compared to those receiving usual care [8]. Many studies have focused on the elderly with medical conditions such as diabetes or rheumatoid arthritis [9-11]. Less is known about foot care carried out by the healthy elderly themselves. Evidence suggests that those who receive regular instructions for foot care at home continue the self-care with beneficial results [12]. As the healthy elderly have a reported poor awareness of foot care [13], there is a clear need for preventative self-care programs. To our knowledge, no intervention studies have examined the impact of foot-care instruction amongst healthy elderly individuals living independently.

We aimed to assess the effectiveness of a foot-care awareness program for the healthy elderly, and compare participants with a control group that did not receive 
foot-care instruction. We assessed whether the program improved foot morphology, physical functioning, and reduced falls, and examined whether it could be used independently without specialist instruction.

\section{Main text \\ Methods \\ Participants}

Twenty-seven participants were recruited from a Community Comprehensive Care Center that provides health support for the elderly in Kanazawa, Ishikawa prefecture, Japan. Individuals attending a dementia prevention workshop were invited to participate. Inclusion criteria were healthy individuals aged 60 and over who required no support for daily living, could carry out their own foot care, and lived in the jurisdiction of the care center. "Foot care" in this study refers to foot examination, cleaning, massage, and toe exercises carried out independently on a daily basis.

\section{Ethical considerations}

Participants were informed that participating or leaving the study would not result in any disadvantage and that personal information would be protected. We obtained written consent from all participants. We offered all members of the control group the full foot-care program at the end of the study. The Kanazawa University Medical Ethics Committee approved the study (approval\# 478).

\section{Intervention and control groups}

The intervention group comprised of 17 women attending the dementia workshop in 2013. They attended lectures and practice sessions by nurses and a physiotherapist in the research team and were asked to perform foot care at home for 6 months whilst receiving support and periodic status check-ups. The control group were ten women of a similar age who had attended the same dementia workshop in 2011 and 2012, and were attending a further workshop in 2013. The study was conducted between December 2013 and June 2014.

\section{Program content}

The self-sufficiency course A 90-min lecture/practice session was held weekly for two continuous weeks for those in the intervention group. The researchers created the program content with reference to foot anatomical physiology, foot-care publications, and other resources $[14,15]$. Session one explained foot structure and function and practiced foot-care examination. Session two explained foot-care techniques and included a further practice session. Foot-care techniques were a combination of existing methods $[15,16]$ and resources from the Japanese Soci- ety for Foot-care covering: examination, washing, nailclipping, toe exercise, massage, and appropriate footwear. A one-page instruction sheet on massage techniques and toe exercises was created to refer to. We encouraged participants to perform foot care at least weekly, as recommended by professionals $[15,16]$, and to complete a footcare calendar to record when foot examination, massage, and toe exercises were carried out.

Periodic status check/support A content-repetition lecture for ensuring foot-care awareness was held after 3 months. The intervention group received monthly phone calls for support, check foot-care status, and collect calendar entries.

Evaluation Evaluation was carried out 6 months before and after the program implementation. Demographic information was collected from participants in the intervention and control groups on: gender, age, living circumstances, hospital attendance, and visibility levels. All participants were asked whether they could walk unaided for 15 min continuously and if any falls had occurred in the past 6 months. Daily life skills were assessed using the 13-item Tokyo Metropolitan Institute of Gerontology Index of Competence (TMIG-IC), to measure independence, intellectual activity, and social role. A point is scored for each item with higher scores indicating greater functional capacity.

Foot morphology and plantar pressure distribution were measured using the Foot View Clinic device (Nitta Corporation, Osaka, Japan). Nine subjective foot movements were examined: toe movement, toe spreading, balance when walking/standing, stumbling, foot lift when climbing stairs, tiredness when walking, foot ground contact sensation, coldness in feet, and foot cramps [6, 13]. These were rated on a four-point scale with a higher score representing worse foot movement.

Foot type was categorized as: standard (grounded foot); weakened (flat foot tendency); flat; hollow; and supinated (highly pressurized state on the heel and fifth toe) [17]. Changes in subjective foot movement and foot type at follow-up were evaluated as "improved," "maintained," "unchanged," or "worsened."

Physical function was assessed by: (1) walking ability speed of walking 14 meters in a straight line; (2) muscle strength (toe-grip power)-seated participants gripped the researcher's finger with their first and second toe without heel-lift and the grip was measured using a digital grip force meter (Takei Instrumentation Industry Co., Ltd.); (3) functional reach-subjects raised their arms with both feet spread and leant forward without heellift to press a bar attached to a ruler (Aussie Co., Ltd). 
The distance of the bar was then measured, taking into account the participant's age.

Members in the intervention group assessed the program utilizing a four-point scale to rank the opening and follow-up lectures, and the monthly support checks.

Statistical analysis Foot-care implementation rate was calculated by dividing the number of days checked on the calendar by the number of days during the period. McNemar's test compared data before and after the program implementation. Chi square tests compared the measurements between the intervention and control groups. Wilcoxon signed-rank tests compared measurements at baseline and follow-up for the intervention group and functional reach measurements for both intervention and control groups. T-tests compared pressure point measurements in the intervention group at baseline and follow-up. Significance was set at 5\%. We used SPSS version 22 (Chicago, IL) for the analysis.

\section{Results}

\section{Baseline characteristics}

Eleven of the 17 participants were included in the intervention group; six discontinued because of personal/ family sickness or time constraints. All participants were women, with an average age of 71.8 years $(S D \pm 7.1)$ in the intervention group and $74.3(\mathrm{SD} \pm 4.7)$ in the controls. Approximately $80 \%$ of participants in both groups exercised regularly. The average TMIG-IC score was $11.9 \pm 1.2$ and $12.1 \pm 1.4$ in the intervention and control groups respectively, indicating good functional capacity. All participants in the intervention group and 90\% of the control group could walk unaided for $15 \mathrm{~min}$ continuously. One participant in each group had fallen in the 6 months before implementation. There were no further falls in the intervention group in the subsequent 6 months whilst four (40\%) of the control group had fallen.

\section{Foot-care implementation}

Nine participants carried out foot care at least weekly. The average ratio of implementation was $65.6 \%$ (5 days/ week) for foot observation, $61.8 \%$ (4-5 days/week) for foot massage, and 70.6\% (5-6 days/week) for toe exercises.

\section{Foot morphology/plantar pressure distribution}

In the intervention group, one participant's foot morphology was flat-footed at baseline but this had resolved 6 months later. Two participants with plantar pressure biased to the outer foot showed front/rear pressure distribution at follow-up, with one developing a visible medial longitudinal arch. Two participants with lower pressure on the first toe versus other toes improved 6 months later (Table 1).

\section{Subjective foot movement}

Ten participants improved or maintained toe movement and toe spreading, nine improved or maintained foot ground contact sensation, and eight maintained or

Table 1 Plantar pressure balance in intervention and control groups

\begin{tabular}{|c|c|c|c|c|c|c|}
\hline \multirow[t]{2}{*}{ Pressure point } & \multirow{2}{*}{$\begin{array}{l}\text { Intervention group }(n=11) \\
\text { Control group }(n=10)\end{array}$} & \multicolumn{2}{|l|}{ Baseline $^{a}$} & \multicolumn{2}{|c|}{6 month follow-up } & \multirow[t]{2}{*}{$a: b^{2} p$ value } \\
\hline & & Mean \pm SD & $p$ value $^{1}$ & Mean \pm SD & $p$ value $^{1}$ & \\
\hline \multirow[t]{2}{*}{ Right } & Intervention & $48.8 \pm 4.8$ & \multirow[t]{2}{*}{0.63} & $51.5 \pm 7.1$ & \multirow[t]{2}{*}{0.22} & \multirow{2}{*}{$\begin{array}{l}0.12 \\
0.94\end{array}$} \\
\hline & Control & $47.7 \pm 5.6$ & & $47.8 \pm 6.4$ & & \\
\hline \multirow{2}{*}{$\begin{array}{l}\text { Front } \\
\text { right }\end{array}$} & Intervention & $39.5 \pm 9.2$ & \multirow[t]{2}{*}{0.27} & $43.7 \pm 10.5$ & \multirow[t]{2}{*}{0.83} & \multirow{2}{*}{$\begin{array}{l}0.13 \\
0.69\end{array}$} \\
\hline & Control & $43.5 \pm 6.6$ & & $44.7 \pm 9.4$ & & \\
\hline \multirow{2}{*}{$\begin{array}{l}\text { Front } \\
\text { left }\end{array}$} & Intervention & $42.7 \pm 11.9$ & \multirow[t]{2}{*}{0.95} & $47.6 \pm 11.0$ & \multirow[t]{2}{*}{0.49} & 0.05 \\
\hline & Control & $42.4 \pm 11.2$ & & $43.7 \pm 14.2$ & & 0.73 \\
\hline \multirow[t]{2}{*}{ Left } & Intervention & $51.2 \pm 4.8$ & \multirow[t]{2}{*}{0.63} & $48.5 \pm 7.1$ & \multirow[t]{2}{*}{0.22} & 0.12 \\
\hline & Control & $52.3 \pm 5.6$ & & $52.2 \pm 6.4$ & & 0.94 \\
\hline \multirow{2}{*}{$\begin{array}{l}\text { Right } \\
\text { rear }\end{array}$} & Intervention & $60.5 \pm 9.2$ & \multirow[t]{2}{*}{0.25} & $56.3 \pm 10.5$ & \multirow[t]{2}{*}{0.83} & 0.13 \\
\hline & Control & $56.7 \pm 6.8$ & & $55.3 \pm 9.4$ & & 0.64 \\
\hline \multirow[t]{2}{*}{ Left rear } & Intervention & $52.3 \pm 11.9$ & \multirow[t]{2}{*}{0.95} & $52.5 \pm 11.0$ & \multirow[t]{2}{*}{0.49} & 0.05 \\
\hline & Control & $57.6 \pm 11.3$ & & $56.3 \pm 14.2$ & & 0.73 \\
\hline
\end{tabular}

\footnotetext{
1 t-test

2 paired t-test

a Baseline

b 6 month follow-up
} 
improved stability of walking/standing balance and feet lift when climbing stairs (Additional file 1). However, these changes were not significantly different from controls.

\section{Foot-care practice}

At follow-up, all foot-care practices had increased in the intervention group compared with baseline, except applying foot cream and reporting an interest in foot care, which remained unchanged (Additional file 2). However, these differences were not statistically significant, nor was there a significant difference between groups in carrying out foot care.

\section{Comparison of foot form}

Ten (90.9\%) people's foot form in the intervention group had either maintained or improved at follow-up (Fig. 1). This improvement was significantly greater than the controls, of whom three (30.0\%) had maintained/improved foot form $(\mathrm{p}=0.0075)$.

\section{Physical function}

There were no statistically significant differences at baseline and follow-up in the intervention group in improved grip strength, right toe pressure, functional reach, or walking speed (Table 2).

\section{Participants' evaluation}

All participants in the intervention group reported that the lecture and monthly phone calls were beneficial. Two participants who did not make foot-care calendar entries said it was "too troublesome" but responded that they had carried out foot care at least once a week.

\section{Discussion}

We found changes in foot morphology occurred in all participants 6 months after foot care implementation. No falls had occurred in the intervention group, while $40 \%$ of controls had fallen. In particular, increased

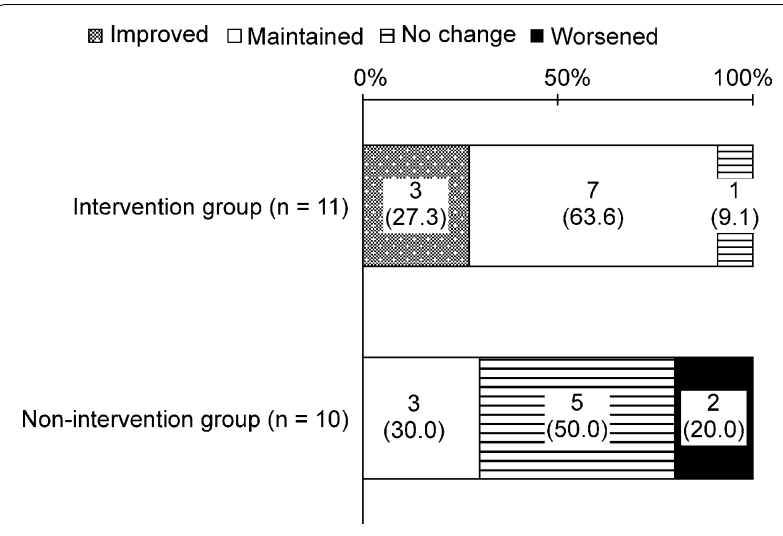

Fig. 1 Change in foot form in the intervention and control groups plantar pressure was observed on the first toe compared to other toes, which is important for effective "kick-out" force whilst walking. These foot changes may be due to improved strength from toe exercising, supporting earlier work that strengthening toe flexor muscles can significantly affect balance ability and reduce falls [5]. Other fall prevention programs have also shown positive results through lower extremity exercises [18]. We found changes in some individuals' center of gravity and arch of the foot, which are important for balance and stability [19]. Regarding subjective foot movement, 90\% of participants showed improved/maintained toe movement and toe spreading, while $70 \%$ showed improved/ maintained foot ground contact sensation and stability of walking/standing balance. An association between toe strength and balance has been reported previously. Nagai et al. [20] found toe and ankle training in those living in nursing homes significantly improved balance ability and reduced the fear of falling.

All participants carried out foot care at least weekly and reported benefits from the mid-term lecture and phone calls. Previous research has shown telephone intervention by nurses is effective in heightening treatment adherence [21]. We believe the supportive telephone calls resulted in participants averaging more than 4 days a week of foot-care. Further, given the greater continuance and higher rate of implementation compared with previous studies [12], our evaluation suggests that this program increases self-care among the elderly and helps maintain and improve independent walking ability.

To conclude, we have shown that foot-care instruction can benefit the independent elderly, particularly in maintaining foot form and improving foot pressure and balance, which may have important implications in fall prevention.

\section{Limitations}

The principal limitation of this study is its observational nature and the non-randomization of participants. Therefore, while we showed an association between the program and health improvements, we cannot determine if this was fully related to the intervention. The study included a small number of participants. This is similar to small-scale studies on lower extremities, including fall prevention in the elderly [18, 22-24]. We did not conduct blind assessment of treatment effects, which may have introduced bias. Our sample included highly able and active elderly people, which may explain the lack of significant improvements in foot morphology and subjective foot movement. We are also unable to generalize our findings to elderly men. Future work should consider the effects of the program at longer follow-up periods, and without support and monthly encouragement. 


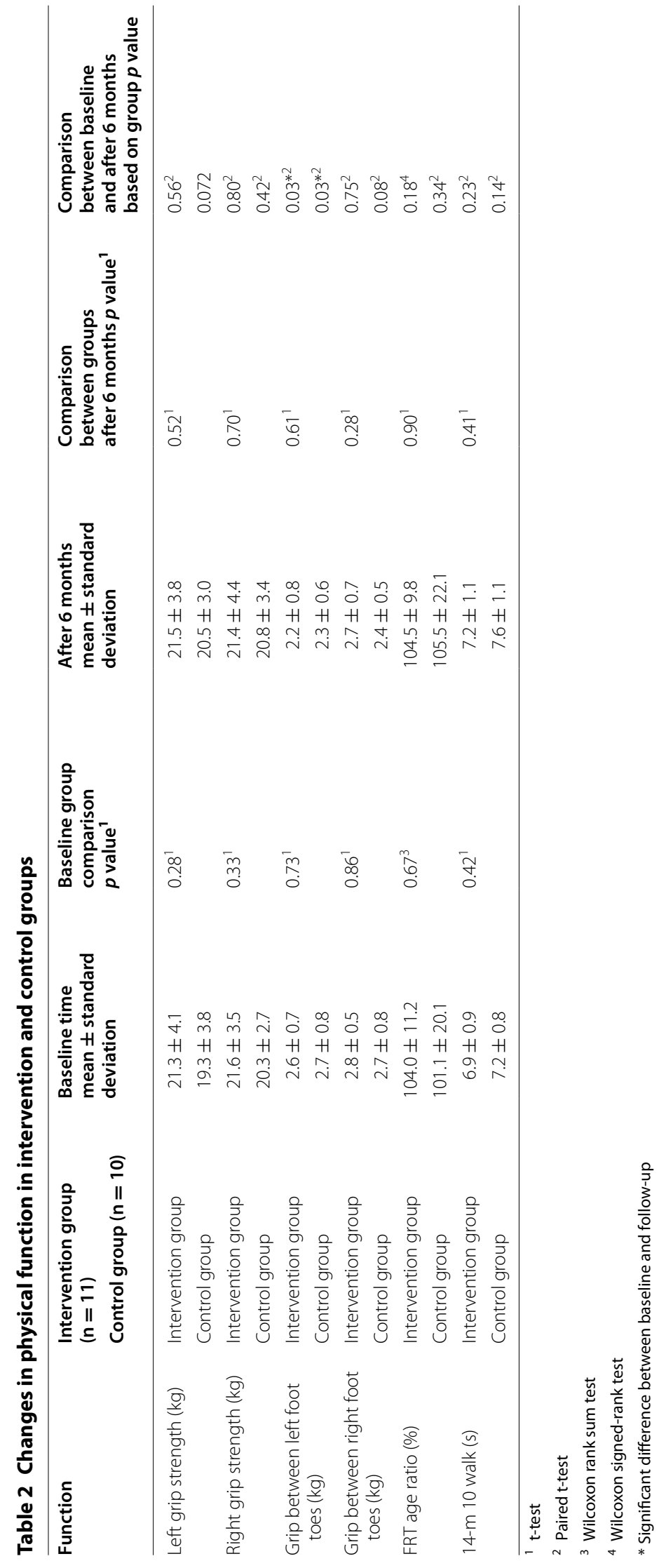




\section{Additional files}

Additional file 1. Subjective foot movement in intervention and control groups.

Additional file 2. Foot-care practice in intervention and control groups.

\section{Abbreviation}

TMIG-IC: Tokyo Metropolitan Institute of Gerontology Index of Competence.

\section{Authors' contributions}

SO conceptualized the research, procured funding, and contributed to the study design, implementation and analyses of the data. AW, TH, and ES contributed to the study design, implementation of the study, and data analysis and evaluation. CS contributed to the implementation of the study and evaluation and analysis of results. MY, RO, Al, KK, and KT contributed to the implementation of the study, data analysis, and evaluation. All authors read and approved the final manuscript.

\section{Author details}

${ }^{1}$ Faculty of Health Science, Institute of Medical, Pharmaceutical and Health Sciences, Kanazawa University, 5-11-80 Kodatsuno, Kanazawa, Ishikawa 920-0942, Japan. ${ }^{2}$ Division of Health Science, Graduate School of Medical Science, Kanazawa University, 5-11-80 Kodatsuno, Kanazawa, Ishikawa 920-0942, Japan. ${ }^{3}$ School of Nursing, Kanazawa Medical University, 1-1 Daigaku, Uchinada, Ishikawa 920-0293, Japan. ${ }^{4}$ Graduate School of Human Health Sciences, Tokyo Metropolitan University, 7-2-10 Higashiogu, Arakawa, Tokyo 116-8551, Japan.

\section{Acknowledgements}

We would like to extend our heartfelt gratitude to everyone who participated in the study. We would like to thank Editage (http://www.editage.com) for English language editing and Publication Support.

\section{Competing interests}

The authors declare that they have no competing interests.

\section{Availability of data and materials}

All data generated or analyzed during this study are included in this published article (and its Additional files).

\section{Consent for publication}

Not applicable.

\section{Ethics approval and consent to participate}

The Kanazawa University Medical Ethics Committee approved the study (approval \#478). Written consent was obtained from all participants.

\section{Funding}

This study was made possible through Grant-in-aid for Scientific Research from the Ministry of Education, Culture, Sports, Science and Technology, Japan (B 25293471).

\section{Publisher's Note}

Springer Nature remains neutral with regard to jurisdictional claims in published maps and institutional affiliations.

Received: 4 July 2017 Accepted: 1 November 2017 Published online: 09 November 2017

\section{References}

1. Robbins JM. Recognizing, treating, and preventing common foot problems. Clevel Clin J Med. 2000;67:45-6.

2. Menz HB, Morris ME, Lord SR. Foot and ankle risk factors for falls in older people: a prospective study. J Gerontol A Biol Sci Med Sci. 2006;61:866-70.
3. Yamashita K, Nomoto Y, Umezawa J, Miyagawa H, Kawasumi M, Koyama $\mathrm{H}$, et al. Affect of shape abnormality in foot and toenail on tumbling of aged. IEEJ Trans Electron Inf Syst. 2004;124:2057-63 (in Japanese).

4. Riskowski JL, Dufour AB, Hagedorn TJ, Hillstrom H, Casey VA, Hannan MT. Associations of foot posture and function to lower extremity pain: results from a population-based foot study. Arthr Care Res. 2013;65(11):1804-12. https://doi.org/10.1002/acr.22049.

5. Kim YW, Kwon OY, Cynn HS, Weon JH, Yi CH, Kim TH. Comparison of toe plantar flexors strength and balancing ability between elderly fallers and non-fallers. J Phys Ther Sci. 2011;23:127-32.

6. Himeno T, Ono M. Effect of foot care for health promotion and disease prevention in elderly persons living at home. Jpn J Nurs Res. 2010;33:11120. https://doi.org/10.15065/jjsnr.20090827007.

7. Murata S, Tsuda A. Prevention of falls in the elderly disabled at home: foot grip strength training. Health Prom. 2005;7:11-8 (in Japanese).

8. Waxman R, Woodburn H, Powell M, Woodburn J, Blackburn S, Helliwell P. FOOTSTEP: a randomized controlled trial investigating the clinical and cost effectiveness of a patient self-management program for basic foot care in the elderly. J Clin Epidemiol. 2003;56(1 1):1092-9.

9. Matricciani L, Jones S. Who cares about foot care? Barriers and enablers of foot self-care practices among non-institutionalized older adults diagnosed with diabetes: an integrative review. Diabetes Educ. 2015;41(1):106-17. https://doi.org/10.1177/0145721714560441.

10. Donohoe ME, Fletton JA, Hook A, Powell R, Robinson I, Stead JW, et al. Improving foot care for people with diabetes mellitus-a randomized controlled trial of an integrated care approach. Diabet Med. 2000;17:581-7.

11. de Souza S, Williams R, Lempp H. Patient and clinician views on the quality of foot health care for rheumatoid arthritis outpatients: a mixed methods service evaluation. J Foot Ankle Res. 2016;9:1. https://doi. org/10.1186/s13047-015-0133-2.

12. Himeno T, Ono M, Magota C. Development of the foot care program for health promotion and disease prevention for elderly persons living at home: second report: effect of foot care performed by elderly persons. Jpn J Nurs Sci. 2014;34:160-9 (in Japanese).

13. Nishida K. Fact finding survey on foot-care of community-resident elderly. Jpn J Med Nurs Educ. 2008;17:44-51 (in Japanese).

14. Takakura Y. Diagram clinical feet. Tokyo: Medical View Co., Ltd; 2010. p. 16-32 (in Japanese)

15. Yamaguchi H. Basic foot-care for nursing practice. Osaka: Medica Shuppan Publishing Co., Ltd.; 2013 (in Japanese).

16. Himeno T, Mieno E, Suehiro R, Okeda T. A fundamental study of foot-care for falls prevention in subjects aged 75 and over living at home. Relationship among structure and function of the foot, history of falling and standing balance. Japanese journal of nursing research. J Jpn Soc Nurs Res. 2004;27:75-84 (in Japanese).

17. Kogawa T, Masakazu T, Kitamiya C, Shibayama E, Ishizaki T, Noda M, et al. The study of the lifestyle and the shapes of the foot soles of the elderly of T town in Aomori Prefecture. Bull Health Sci Hirosaki. 2006;5:55-64.

18. Jeon MY, Jeong HC, Petrofsky J, Lee H, Yim JE. Effects of a randomized controlled recurrent fall prevention program on risk factors for falls in frail elderly living at home in rural communities. Med Sci Monit. 2014;20:2283-91. https://doi.org/10.12659/MSM.890611.

19. Melzer I, Benjuya N, Kaplanski J, Alexander N. Association between ankle muscle strength and limit of stability in older adults. Age Ageing. 2009;38(1):119-23.

20. Nagai K, Inoue T, Yamada Y, Tateuchi H, Ikezoe T, Ichihashi N, et al. Effects of toe and ankle training in older people: a cross-over study. Geriatr Gerentol Int. 2011;11:246-55.

21. Nesari M, Zakerimoghadam M, Rajab A, Bassampour S, Faghihzadeh S. Effect of telephone follow-up on adherence to diabetes therapeutic regimen. Jpn J Nurs Sci. 2010;7:121-8. https://doi. org/10.1111/j.1742-7924.2010.00146.x.

22. Kim MK, Lee YS. Kinematic analysis of the lower extremities of subjects with flat feet at different gait speeds. J Phys Ther Sci. 2013;25:531-3. https://doi.org/10.1589/jpts.25.531.

23. Lee JU, Park GH, Lee YS, Kim MK. A comparison of muscle activities in the lower extremity between flat and normal feet during one-leg standing. J Phys Ther Sci. 2013;25:1059-61. https://doi.org/10.1589/jpts.25.1059.

24. Kim J, Kim K, Gubler C. Comparisons of plantar pressure distributions between the dominant and non-dominant sides of older women during walking. J Phys Therapy Sci. 2013;25:313-31. https://doi.org/10.1589/jpts.25.313. 